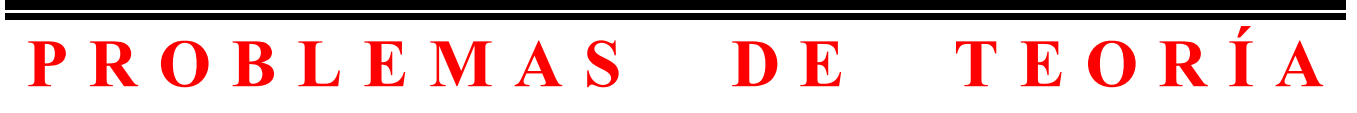

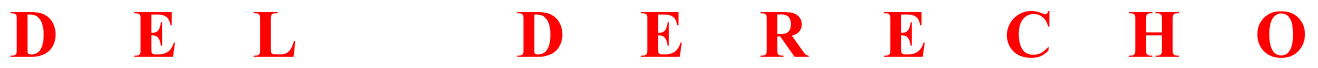




\section{GEOGRAFÍA DE LAS NORMAS DE COMPETENCIA *}

\section{Objetivo}

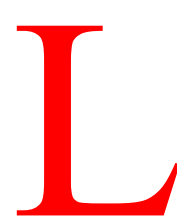

a invitación de Letizia Gianformaggio a participar en el V Congreso Kelseniano -Siena, mayo 1993- tuvo la virtud de obligarme a trabajar un tema que se considera importante en la tradición analítica pero que me ha dejado perplejo. En este trabajo pretendo -en primer lugar- mostrar de una forma sintética cómo la doctrina ha resaltado la importancia de las normas de competencia, y, al mismo tiempo, no ha sido capaz de avanzar en una construcción conceptual suficientemente compartida. En la introducción trataré de poner de manifiesto las inseguridades y las ambigüedades de algunos autores importantes.

En una segunda fase voy a sugerir que los autores analizados -que han tratado este tema- han intentado ofrecer un concepto unitario de normas de competencia de tal forma que todas aquellas entidades que usualmente se denominan normas de competencia tienen un conjunto de propiedades comunes. Mi posición es que se comete la falacia de la composición al tratar de imponer unas propiedades a todas las clases de normas de competencia porque se parte de un caso ejemplar muy concreto -y en el que todo el mundo está de acuerdo- y se infiere de él las propiedades que toda norma de competencia debe tener. Sostendré que las diversas doctrinas incurren en el vicio de esencialismo y argumentaré por qué conviene desterrarlo.

En una tercera fase sugeriré una vía para comprender las normas de competencia. Creo que las normas de competencia no sólo son relevantes para las instituciones aplicadoras del derecho -como afirma

* Esta investigación ha sido posible gracias a la ayuda ofrecida por la CIRIT y la DGCYT al equipo de profesores de la Universitat Pompeu Fabra. Debo agradecer especialmente a Ricardo Caracciolo y a Juan Ruiz Manero sus comentarios y críticas. 
Raz- sino que también para las productoras de derecho y para otro tipo de reglas que hacen referencia a las normas. Un primer criterio de clasificación que utilizaré es el de la distinción entre normas de conducta y normas que hacen referencia a otras normas -que denominaré metarreglas-. La noción de metarreglas que Hart sugirió puede ser ampliada con un modelo que ofrezca una muestra más completa de los distintos tipos de metarreglas que denominaremos normas de competencia.

Otro buen criterio de clasificación para completar nuestra geografía será tener en cuenta cuáles son las consecuencias jurídicas del seguimiento de las normas de competencia. Los conceptos más básicos a utilizar serán el de la inexistencia, la anulabilidad y la sanción como ha sugerido Ricardo Guastini. Y convendrá señalar ya de buen principio que la anulabilidad tiene diversos grados. También cabría tener en cuenta que -en muchas ocasiones- las teorías tropiezan con problemas difíciles de resolver, como es la exigencia de la aceptación de un presupuesto muy fuerte según el cual la actividad estatal es siempre actividad jurídica y que permite -en principio- validar las decisiones de la administración como correctas jurídicamente mientras que no ocurre lo mismo con las privadas. Eso debe relacionarse con ciertos privilegios -no superados- que tiene la autoridad incluso cuando obra fuera de su competencia. En el fundamento del argumento podemos encontrar la idea de que no se puede suponer sin mas que la actividad estatal es siempre actividad jurídica. En el trasfondo del problema se encuentra la cuestión que tanto preocupó a los clásicos: ¿es posible limitar el gobierno?, ¿cuáles son las normas que todo gobierno debe respetar?

\section{Institucionalización y reglas de competencia}

Existe un amplio acuerdo en la doctrina sobre el carácter institucional del derecho. El derecho es uno de los sistemas normativos mejor organizados e institucionalizados que nos envuelve aunque conviene señalar que existen otros sistemas normativos institucionalizados que no son sistemas jurídicos ${ }^{1}$. Los juristas acostumbran a tratar los problemas de la institucionalización como si fueran condiciones necesarias y suficientes para poder hablar del derecho. Sin embargo, conviene ser conscientes de que el mundo normativo que nos envuelve es muy complejo y que la institucionalización es condición

${ }^{1}$ Tal es el caso de algunos juegos. Véase sobre este punto el trabajo de J. Raz: Razón Práctica y Normas, Madrid, Centro de Estudios Constitucionales, 1991, capítulo 4. 
necesaria pero no suficiente de la existencia del derecho. De la misma forma que los juegos no son sólo un conjunto de reglas, sino que exigen compartir el valor del juego -ganar por ejemplo- el derecho puede ser considerado como un conjunto ordenado de normas, pero que tiene ciertas pretensiones necesarias -como las de comprehensividad, autoridad suprema y la de constituir sistemas abiertos- para que se pueda predicar su existencia.

Ahora bien, ¿qué entendemos por institucionalización? Una primera aproximación intuitiva nos muestra que la institucionalización está relacionada con la organización de las actividades de los órganos del estado conforme a algunas reglas básicas. La idea de institucionalización hace referencia a la idea de organización y de orden, es decir, a la idea de que el sistema ofrece respuestas previsibles, seguras y reiterables, a la idea de que el sistema se innova a través de procedimientos establecidos. La institucionalización se realiza a través de reglas.

Raz ha insistido especialmente en el carácter institucional del derecho y ha resaltado la importancia de sus instituciones aplicadoras. El criterio que utiliza Raz no es el de la función que realizan los órganos del estado, sino el de la forma mediante la cual la ejercen. Según Raz los sistemas jurídicos no se identifican sólo por el hecho de que contiene normas que confieren potestades o facultades para pronunciar determinaciones aplicativas de carácter obligatorio. Los sistemas jurídicos tienen que contener normas que confieren tales poderes o facultades a instituciones. Raz considera que lo que caracteriza al derecho positivo es ese poder para determinar autoritariamente la solución de problemas jurídicos. Parece ser pues que para identificar un sistema jurídico es preciso hacer referencia a esa institucionalización que se realiza a través de reglas que confieren poderes o facultades. La existencia de reglas de competencia -según Raz- es necesaria para la existencia del derecho, pero de ello no cabe inferir que si identificamos una norma de competencia entonces este sistema normativo es un sistema jurídico ${ }^{4}$.

La insistencia de Raz sobre el carácter institucional del derecho y -especialmentesobre el papel de las normas de competencia, no representa una novedad. Las normas de competencia juegan un papel muy importante en la teoría de los sistemas normativos. Existe acuerdo en la doctrina sobre su importancia. Sin embargo, no existe acuerdo sobre su estatuto normativo ni incluso sobre su función ${ }^{5}$, de tal forma que bien se podría afirmar que existe un acuerdo sin que se

${ }^{4}$ Véase J. Raz, La autoridad del Derecho, UNAM, 1982, especialmente págs. 143 y ss.

${ }^{5}$ Un buen resumen de la reciente historia puede verse en el trabajo de Daniel Mendonca, Introducción al Análisis Normativo, Madrid, Centro de Estudios Constitucionales, 1992, que he utilizado con provecho. 
sepa exactamente cuál es el contenido significativo del mismo.

Para confirmar esta idea convendría analizar la posición kelseniana. En su Teoría General del Derecho y del Estado, pág. 3, Kelsen sugiere que «el derecho es un orden de la conducta humana. Un orden es un conjunto de normas. El derecho no es, como a veces se dice, una norma. Es un conjunto de normas que tiene el tipo de unidad a que nos referimos cuando hablamos de sistema. Es imposible captar la naturaleza del derecho si limitamos nuestra atención a una sola norma aislada. Las relaciones entre las normas de un orden jurídico son también esenciales a la naturaleza del derecho. Únicamente sobre la base de una clara comprensión de las relaciones que constituyen un ordenamiento jurídico, puede entenderse plenamente la naturaleza del derecho» ${ }^{6}$.

Kelsen sostuvo que el sistema jurídico estaba compuesto por diversos elementos y se encuentra en el origen de una literatura sumamente sugestiva que ha ido depurando las ideas base de la teoría general de los sistemas normativos. Además, afirmó que las normas de competencia son normas dependientes de las normas de conducta y eso quiere decir que aquéllas sólo tienen sentido si se establece su relación con las normas independientes -que son las que establecen sanciones. Sin embargo, algunos autores como, por ejemplo, Raz, y en mayor medida Paulson, sostienen que la norma básica kelseniana es fundamentalmente una norma de competencia y, por tanto, sugieren -especialmente Paulson- que la tesis de la dependencia de las normas de competencia debe ser matizada y que es posible sostener que «la modalidad de conferir poderes es fundamental, lo cual significa, entre otras cosas, que las otras modalidades legales se construyan a partir de aquélla» ${ }^{7}$.

En Reine Rechtslehre, 1960, y después en Allgemeine Theorie der Normen, Kelsen, explicó las diferentes funciones que cumplen los elementos que forman parte del sistema. Señaló que las normas tienen la función de ordenar, permitir, autorizar o derogar. Bajo el término general de autorización incluyó las ideas de capacidad, competencia,

${ }^{6}$ Véase H. Kelsen, Teoría General del Derecho y del Estado, México, UNAM, 1969.

${ }^{7}$ Tuve la oportunidad de escuchar la argumentación de Paulson en Siena en el V Congreso sobre la obra de H. Kelsen, y el propio Paulson me proporcionó el texto básico de la argumentación titulado «On the Systemation thesis in Kelsen's Pure Theory of Law», pág. 5. Véase también J. Raz, «La Teoría de Kelsen de la Norma Fundamental» en J. Raz; Autoridad del Derecho, op. cit., pág. 163, en la cual sostiene que la norma fundamental es una disposición jurídica que confiere potestades. Sobre este punto Kelsen es muy explícito en su Reine Rechtslehre \& 6d y en «Der Begriff der Rechtsordnung», I, Logique et Analyse, 1958, reprinted in Die Wiener Rechtstheoretische Schule, vol. 2, págs. 1.395-1.400 por la que se cita. 
imputación y poder jurídico. Sostuvo -además- que las diferencias entre estos conceptos no son sustanciales y que corresponden a una función normativa que atribuye a un individuo la posibilidad de crear o aplicar normas (cap. XXVI de Allgemeine Theorie der Normen). Según Kelsen las normas de competencia son normas que autorizan ${ }^{8}$.

Ha sido mérito indudable de Kelsen el poner énfasis en que el derecho no es sólo norma coactiva, aunque la conceptualización de las normas de competencia es cuanto menos confusa en su teoría9. En todo caso, la mayoría de los autores tratan de ver en el planteamiento kelseniano un prototipo de normas de competencia como normas dependientes de las normas de conducta. Pero esta posición no es compartida puesto que hay autores que defienden que las normas de competencia poseen un estatus independiente -tal sería el caso de Hart, Bulygin o de Raz ${ }^{10}$.

\section{El estatuto de las reglas de competencia}

A partir de Kelsen el análisis de las normas de competencia ha sido uno de los grandes temas que ha ocupado a la mejor teoría analítica contemporánea. Las aportaciones de Hart, Ross, von Wright, Raz y Alchourrón y Bulygin son un buen ejemplo. Cuando nos preguntamos sobre el estatuto de las normas de competencia nos preguntamos si son normas que permiten o prohíben una conducta determinada o si bien tienen un estatuto distinto. En el seno de esta segunda respuesta se han ofrecido muchas variables.

Existen muchos planteamientos distintos sobre las normas de competencia.

${ }^{8}$ Sobre la teoría kelseniana de las normas de competencia véase S. Paulson, An Empowerment Theory of Legal Norms, Ratio Iuris, I, 1988. Paulson sostiene que existen varias interpretaciones posibles en la teoría de las normas de competencia en Kelsen. Ver especialmente págs. 69 y s., en la que sugiere una doble interpretación complementaria de las normas de competencia en la cual el mandato de imponer la sanción deriva de la modalidad que confiere la competencia que es primitiva. Véase también el trabajo de R. Caracciolo, «Some observations about power conferring norms», presentado en el Congreso de Siena y todavía no publicado, en el que muestra algunas antinomias en el pensamiento kelseniano sobre las normas de competencia (se publicará en Analisi e Diritto).

${ }^{9}$ Sobre el problema de las normas de competencia en Kelsen véase el trabajo de Harris: «Kelsen's Concept of Authority», en Law Cambridge Journal, 1977, y la polémica entre S. Paulson y R. Vernengo, aparecida en Ratio Iuris, vols. 1 y 2, años 1988-89. La discusión se centra -entre otras cosas- en la forma lógica y el carácter normativo de las normas de competencia.

${ }^{10}$ Véase H. Hart, The Concept of Law, Oxford, Clarendon Press, 1961; Bulygin, Sobre las normas de Competencia, en Alchourrón y Bulygin, Análisis Lógico y Lenguaje, Madrid, Centro de Estudios Constitucionales, 1991. J. Raz, El concepto de Sistema Jurídico, México, UNAM, 1986, págs. 267 s. 
Algunos autores -como ya hemos visto, por ejemplo, Kelsen- reducen las normas de competencia a normas imperativas en tanto las normas de competencia forman parte de una norma jurídica completa que incluye una sanción ${ }^{11}$.

Una posición que también asocia las normas de competencia con las normas de conducta es la seguida por Alf Ross. Este autor ha hecho referencia a algunos aspectos sumamente importantes acerca de su contenido, su forma y el sujeto. Su posición es a veces ambigua, pero en líneas generales se podría afirmar que sostiene que las normas de competencia pueden ser reducidas a normas de conducta ${ }^{12}$. Ross sostiene que las normas de competencia son normas de conducta formuladas indirectamente y «cada norma de competencia define un acto jurídico que indica las condiciones para el establecimiento de un acto jurídico válido. Estas condiciones pueden ser divididas en tres grupos que determinan, en primer lugar, el órgano competente para dictar el acto jurídico. En segundo lugar, el procedimiento de competencia formal. En tercer lugar, el contenido posible del acto jurídico ${ }^{13}$. Uno de los problemas fundamentales que surgen es establecer las condiciones bajo las cuales se pueden reducir todas las normas de competencia a normas de conducta y Ross señala dos. La primera es que los órganos deben seguirla. Es decir, se presupone que no se salen nunca de la competencia y que los órganos del estado actúan legalmente siempre y en toda circunstancia. La segunda condición es que el órgano del estado tiene responsabilidad por su no seguimiento ${ }^{14}$. Como veremos estas dos condiciones no son plausibles por muchas razones. Primero, porque es

${ }^{11}$ La noción de norma jurídica sugerida por Kelsen aparece en sus Hauptprobleme der Staatsrechtslehre, Tübingen, Mohr, 1911, pág. 237, en donde afirma que «la norma jurídica -en su forma ideal- debe ser construida desde la perspectiva del contenido de las leyes y algunos componentes necesarios para esta construcción a menudo no se encuentran la misma ley, sino que debe ser reconstruido teniendo en cuenta diversas leyes».

${ }^{12}$ On Law and Justice, London, Steven and Sons, pág. 32.

${ }^{13}$ On Law and Justice, op. cit., pág. 204.

${ }^{14}$ Véase On Law and Justice, op. cit., en la cual sostiene que para que las normas de competencia puedan formularse como normas de conducta es preciso que se dé algunas de estas dos condiciones: «The construction is possible if the norms of competence have the effect of voidability. This means that the courts are ordered to apply only those rules of conduct which were created in accordance with the conditions of the norm of competence... The construction is possible also, even in the absence of any effect of avoidability, if the norm of competence have the effect of responsability. This means that the courts -perhaps a special court- are directed to order sanctions against the person responsable for excess of competence», y poco más adelante, reconoce, «If however, a norm of competence has neither of these effects, the constitution of it as an indirectly formulated norm of conduct directed to the courts is not possible». 
un hecho bastante frecuente que los órganos del estado actúen fuera de su competencia y -segundo- porque en algunos casos no se atribuye responsabilidad por no seguir las reglas de competencia. Especialmente cuando la autorización del estado tiende a promover positivamente una directriz o una finalidad determinada. Obsérvese pues que la teoría de Ross concuerda con la de Kelsen en la importancia de las normas de competencia: «el derecho consiste no sólo en normas de conducta, sino también en normas de competencia, las cuales establecen el conjunto de autoridades para dictar normas de conducta y para ejercitar la fuerza en conformidad con éstas», pág. 59. Sin embargo, también es ambiguo cuando subordina las normas de competencia a las normas de conducta introduciendo condiciones excesivamente fuertes. En Directives and Norms, pág. 120, Ross confirma su tesis principal cuando afirma que «cualquier norma de competencia puede ser convertida en una norma de conducta mientras que a la inversa no funciona».

Pocos autores han insistido tanto sobre la importancia de las normas de competencia como Hart. Su modelo es muy sencillo pero ofrece -sin dudas- un cuadro general del derecho muy simplificado en el cual las normas secundarias ocupan un lugar muy importante. Hart fue muy consciente de que su modelo supersimplificaba las cuestiones y ofreció algunas reflexiones que pueden ser muy útiles para continuar trabajando sobre el tema. No quisiera insistir sobre este punto en demasía. Simplemente quisiera constatar que Hart también se mueve en esa dirección de ofrecer una explicación del derecho valiéndose de las normas de competencia. Hart superpone los tipos de normas -de conducta o las que confieren potestades- con las funciones que ejercen de ordenar la conducta o de servir para organizar la creación, aplicación e identificación del derecho ${ }^{15}$. También fue consciente de que su modelo era incompleto e hizo algunas sugerencias mostrando algunas vías para completarlo.

Hart sostuvo que el ordenamiento jurídico está compuesto por normas primarias y por normas secundarias y atribuyó una importancia excepcional a la introducción de esa distinción comparándola con la invención de la rueda ${ }^{16}$. Afirmó que las normas que confieren

${ }^{15}$ Para una crítica de la tesis de Hart véase J. Raz: Las funciones del Derecho en J. Raz: la Autoridad del Derecho, op. cit., pág. 224, en la cual afirma que la teoría de Hart oscurece el hecho de que los sistemas jurídicos realizan dos funciones primarias muy importantes, la provisión de servicios y la resolución de disputas no reguladas. Según Raz la distinción entre normas primarias y normas secundarias está hecha para servir dos propósitos incompatibles. En algunas ocasiones es considerada como una distinción entre tipos normativos y, en otras, como distinción entre funciones sociales.

${ }^{16}$ Véase la pág. 41 de The Concept of Laws, op. cit. 
potestades son distintas a las normas de conducta porque éstas llevan aparejadas sanciones mientras que las normas de competencia no son normas de conducta y, por tanto, no originan -no son los antecedentes de- las sanciones. Sugirió además que en el ordenamiento jurídico existen distintos tipos de reglas y que las unas no son dependientes de las otras ${ }^{17}$. El incumplimiento -o el no seguimiento- de una norma secundaria no origina una sanción, sino algún tipo de nulidad. Y Hart ha insistido como ningún otro autor en la tesis de que la nulidad no es una sanción ${ }^{18}$. Carece de sentido afirmar que el tribunal que se ha constituido ilegalmente será sancionado. Si tomamos en serio la sugerencia de Hart quizá podríamos afirmar que las reglas constitutivas se diferencian de las reglas regulativas en que el no seguir una regla constitutiva origina una posibilidad de nulidad, mientras que el no seguir una norma regulativa puede originar una sanción ${ }^{19}$. Hart es firme defensor de la tesis del estatuto independiente de las normas que confieren potestades. Ese estatuto es distinto por su objeto -porque las normas secundarias tienen como objeto otras normas- y por las consecuencias jurídicas, porque la nulidad es una consecuencia distinta a la sanción.

Otros autores -como por ejemplo Sundby- sugieren que junto a las normas de conducta existen unas disposiciones cualificatorias como una categoría independiente de normas. Las disposiciones cualificatorias son una clase de normas que determinan las acciones lingüísticas que deben ser aceptadas como actos creadores de normas ${ }^{20}$. Esta tesis ha tenido algunos seguidores en España, concretamente Hernández Marín utiliza esta terminología. El principal problema con el que se enfrenta esta teoría es que las consecuencias jurídicas del no seguimiento de una disposición cualificatoria no siempre son

\footnotetext{
${ }^{17}$ Raz también considera que existen diversos tipos de normas jurídicas -unas que imponen deberes y otras que confieren facultades-. Además de estas normas existen disposiciones jurídicas que no son normas como, por ejemplo, las disposiciones existenciales que son las que crean, destruyen o regulan la existencia o no existencia de entidades. Véase su Concepto de Sistema Jurídico, op. cit., pág. 267. Véase sobre este punto T. Honoré: Real Laws, en Hacker y Raz eds., Law, Morality and Society, Oxford University Press, 1977, pág. 122, en donde hace una clasificación de las disposiciones no normativas.

${ }^{18}$ Véase su The Concept of Law, cap. 3, págs. 33 y s.

${ }^{19} \mathrm{La}$ distinción entre normas primarias y secundarias es semejante a la distinción que Ross establece entre normas de obligación y de competencia. Hart no es muy riguroso en esta distinción y C. F. H. Trapper ha distinguido ocho distintos significados de la distinción. Véase su trabajo «Powers and Secondary Rules», en A. W. Simpson ed.,Oxford Essays in Jurisprudence, Oxford University Press, 1973, págs. 248 y s.

${ }^{20}$ Sobre este punto véase el artículo de T. Stromberg: Norms of competence in Scandinavian Jurisprudence, in A. Peczenick et als. eds. Theory of Legal Science, Institut for Scandinavian Law, Stockholm, 1984.
} 
las mismas y es muy difícil tener un criterio sobre qué norma es cualificatoria y qué norma es a la vez una norma de conducta. Un modelo que sugiera que del no seguimiento de una disposición cualificatoria se sigue la inexistencia, tiene el problema que describe sesgadamente la realidad jurídica porque si las autoridades no siguen las disposiciones cualificatorias de ello no se desprende necesariamente la inexistencia de una norma jurídica. Otros autores como, por ejemplo, von Wright sugieren que las normas de competencia son permisos. Esta es la posición que Alchourrón y Bulygin siguieron en Normative Systems y esta tesis ha tenido una gran influencia especialmente en los países de habla castellana. Sin embargo, Bulygin ${ }^{21}$ en artículos recientes trata de ver las normas de competencia como reglas constitutivas y trata de diferenciarlas de las reglas regulativas. Las normas de competencia serían definiciones o reglas conceptuales y no tendrían carácter normativo. Bulygin sostiene que no se puede unificar la actividad de definir y prescribir. Una cosa es definir y otra es prescribir. Sin embargo, Bulygin no ofrece los argumentos filosóficos que justifican esa imposibilidad. También en este autor puede advertirse la inseguridad con la que nos encontramos cuando tratamos este problema al pasar de una concepción de las normas de competencia como permisos o autorizaciones a reglas conceptuales. Bulygin tampoco ha explicado de una manera convincente cuáles son las razones por las cuales ha rechazado su posición anterior ${ }^{22}$. Esta falta de explicación es un indicio de la idea que defiendo. Las normas de competencia son muy importantes pero no se sabe mucho sobre ellas. Incluso lo que se sabe se defiende con debilidad.

MacCormick -siguiendo a Searle- sostiene que las normas de competencia son reglas constitutivas y que, por tanto, determinan una actividad. Sin embargo, MacCormick no acierta a ofrecer un buen criterio para distinguir cuándo una regla es constitutiva y cuándo es regulativa porque afirma que toda regla constitutiva tiene algún aspecto regulativo. Si esto es cierto, entonces es muy difícil saber cuándo una regla es constitutiva o regulativa. MacCormick sostiene además que las normas de competencia son dependientes de las normas de conducta y vuelve al planteamiento de inspiración kelseniana. Existe una gran vaguedad acerca del carácter normativo de las normas de competencia en su planteamiento ${ }^{23}$. MacCormick también

${ }^{21}$ La idea de las normas de competencia como reglas conceptuales la ha mantenido Bulygin en una serie de trabajos como, por ejemplo. «Sobre la regla de reconocimiento», y «sobre las normas de competencia» publicados en su antología Análisis Lógico y Lenguaje, ya citado.

${ }^{22}$ En su trabajo sobre las normas de competencia critica las tesis que sostuvo sin citarse y sin explicar el cambio.

${ }^{23}$ Raz critica a Searle -y por extensión a MacCormick- su ambigüedad con buenos argumentos en Razón Práctica y Normas, op. cit., págs. 123 y ss. 
sostiene que las normas de competencia son invenciones de la ciencia y la teoría jurídica y que no existen como tal en el material jurídico preanalítico ${ }^{24}$. MacCormick me parece que se acerca a planteamientos autopoiéticos según los cuales el punto de vista del observador externo es incapaz de reconocer los aspectos más fundamentales del derecho ${ }^{25}$. La teoría que nos ofrece es insatisfactoria porque el criterio de distinción entre reglas constitutivas y regulativas no es claro y porque del hecho de que la invención ocupe un papel importante no se sigue que esas invenciones sean independientes de cualquier control que tenga que ver con la experiencia. Una cuestión es afirmar que existen decisiones subjetivas metodológicas y otra cosa muy distinta es que las normas de competencia sean puramente inventadas e incontroladas.

El repaso que he ofrecido de las posiciones de la doctrina creo que ofrece la posibilidad de confirmar mi primera intuición. Todos los autores analizados consideran que las normas de competencia son muy importantes para comprender los sistemas jurídicos. Son, por tanto, elementos a tener en cuenta para la construcción de una teoría del sistema normativo. Pero también el análisis efectuado muestra que no existe acuerdo y que, en principio, se ofrecen muchas respuestas a la pregunta acerca del estatuto de las normas de competencia. Para algunos son dependientes de las normas de conducta y sólo tienen sentido en relación con ellas. Tal es la interpretación mayoritaria de la teoría de Kelsen y de Ross. Pero, sin embargo, ambas teorías tienen sus puntos débiles y la teoría kelseniana puede interpretarse también como una teoría que concede un estatus independiente a las normas de competencia. Alchourrón y Bulygin han defendido la idea de que las normas de competencia son autorizaciones. Hart -por otra parte- las identifica con las que confieren potestades y con la idea de nulidad y muestra su estatuto independiente.

${ }^{24}$ He tratado este problema en Power-conferring Rules and MacCormicks proposal, que se publicará en Analisi e Diritto.

${ }^{25}$ Véase sobre este punto los planteamientos de MacCormick en su ponencia en el V Congreso sobre Kelsen, que se publicará próximamente en Analisi e Diritto. La actitud de MacCormick es también muy suave con los Critica Legal Studies y con el Feminismo. Creo que los planteamientos de Teubner le han influido y sostiene que el presupuesto que el derecho se autocrea es una prueba de la idea del derecho autopoiético y de las tesis de la circularidad sostenidas por Teubner. Teubner en su Law as Autopiesis System, Oxford, Blackwell, 1993, sostiene que la circularidad que hasta hace poco tiempo había sido considerada como un inaceptable modo de conocimiento se observa ahora como una práctica valiosa y productiva desde el punto de vista heurístico, pág. 9, pero no ofrece los argumentos epistemológicos que justifican este cambio. 


\section{Esencialismo y normas de competencia}

El siguiente paso de mi argumento será explicar la razón por la cual existe tanta confusión: quisiera sugerir que una de las razones por las cuales existe tanta confusión es porque se presupone que todo lo que se denomina usualmente «normas de competencia» corresponde a una estructura unitaria que tiene unas propiedades comunes. Cuando se nos sugiere que las normas de competencia son definiciones se nos ofrecen buenos ejemplos que corroboran la tesis, pero también existen algunas normas de competencia que dan instrucciones, que hacen referencia a plazos o que señalan la competencia material o el marco de actuación y todo esto no cabe en nuestro concepto tal y como ha sido definido. Lo mismo ocurre cuando asociamos las normas que confieren poderes a la nulidad. Existen casos en los que, sin duda, se produce -o se puede producir- la nulidad, pero cuando se incumplen algunas normas a veces estas normas son normas de conducta y a veces estas normas de conducta pueden originar sanciones, pero a veces no, como ya veremos más adelante. También nos podemos encontrar casos en los cuales la norma no existe o se produce una apariencia de norma. Quisiera afirmar, por tanto, que en la tradición analítica todavía pervive una fuerte dosis de esencialismo cuyos defectos puso de manifiesto magistralmente Carlos $\mathrm{Nino}^{26}$.

Parece quizá un camino más interesante evitar el esencialismo y ofrecer una clasificación de las distintas normas de competencia sin el prejuicio de que todas deben tener las mismas propiedades y luego analizar las consecuencias jurídicas de su no seguimiento o de su infracción en su caso -si es que las normas de competencia se pueden infringir.

Una propuesta de clasificación. Normas sobre la producción, la aplicación y el conflicto

Ricardo Guastini, en un artículo todavía inédito ${ }^{27}$, ha sugerido una clasificación entre las normas de competencia que me parece útil. Vamos a tratar las normas de competencia como metarreglas, es decir, como reglas que tienen como objeto normas. Desde esta perspectiva podemos preguntarnos qué tipos de metarreglas podemos

${ }^{26}$ Véase C. Nino, Derecho Moral y Política, Barcelona, Ariel, 1994, págs. 23 y ss.

${ }^{27}$ Cito de una vez por todas este excelente trabajo de Ricardo Guastini titulado Invalidity -que se publicará en un libro homenaje a Ernesto Garzón Valdés-, que he seguido muy de cerca en algunos de sus argumentos. 
encontrar en un ordenamiento jurídico desarrollado. La única propiedad común que atribuimos a las metarreglas es que tienen como objeto otras normas o reglas y no suponemos ni que son autorizaciones o definiciones o normas de conducta, pero que lo pueden ser. Ese puede ser una buen inicio para -sin animo de ser exclusivo- ofrecer un modelo que sirva para orientarnos y que permita avanzar en el conocimiento, construcción y clasificación de las normas de competencia.

Guastini trata de no ser reduccionista y para conseguir este objetivo establece una distinción entre las normas de competencia que sirven a la producción del derecho y normas de competencia que sirven para la aplicación del derecho. Asimismo, sugiere una tercera categoría de normas de competencia que denomina normas sobre los conflictos. Frente a la tesis reduccionista kelseniana según la cual todas las normas de competencia son autorizaciones y todas pertenecen al mismo género, creo que es interesante apreciar las diferencias que existen entre las diversas normas de competencia. Porque nada asegura que estos tipos de normas de competencia se corresponda con una tipología unitaria.

\section{Normas sobre la producción}

Denominaremos normas sobre la producción todas aquellas metarreglas que tengan como objeto la creación de las normas jurídicas. En general la teoría ha prestado más atención a las normas de competencia sobre la aplicación que a las que tienen como objeto la producción. Cabría también señalar que existen diferencias sustanciales en el régimen jurídico según estas normas sobre la producción traten de regular la creación de constituciones, leyes, reglamentos o normas de derecho privado.

Las normas sobre la producción de normas se pueden clasificar según los siguientes criterios: normas que confieren poderes, normas que regulan procedimientos, normas que regulan las materias y normas que regulan los contenidos concretos de las normas a producir.

Conviene tener en cuenta que las normas que sirven para producir normas no tienen todas las mismas características, y las consecuencias que se siguen de su no seguimiento no son siempre las mismas. Hay algunas normas que confieren poderes para dictar normas jurídicas, pero esas normas pueden tener como destinatarios la constitución de un órgano del estado, o bien, la autorización a un particular o a una entidad jurídica para la creación de normas. Por ejemplo, un particular puede estar habilitado por una ley para producir nuevas normas que se integran en el ordenamiento. Si se extralimita en el 
ejercicio del poder puede ocurrir que no exista la nueva norma, o bien, sea susceptible de nulidad o que este particular realice un acto condición de una sanción. La teoría tiende a sostener -como ya vimos en Ross- que si la norma que confiere poderes no es seguida entonces no se produce una nueva norma. Como veremos esta tesis es equivocada porque existen normas que no se han dictado conforme a los criterios preestablecidos de otorgamiento de poderes $\mathrm{y}$, sin embargo, forman parte del derecho positivo vigente.

Pero éste no es el único tipo de normas de competencia sobre la producción de normas. En el marco de la producción de normas el órgano habilitado para el ejercicio del poder, en muchas ocasiones, no es libre de ejercitarlo como le indique su leal saber y entender. El derecho prescribe qué procedimientos pautados deben seguirse para la creación de normas jurídicas válidas. En algunos casos, no todos, nos encontramos con normas de conducta que van dirigidas a los particulares o a los órganos del estado. Al ser normas de conducta llevan aparejadas sanciones o pueden llevarlas aunque a medida que nos acercamos a la cúspide del poder es más difícil controlar su ejercicio mediante sanciones ${ }^{28}$. En otros casos nos encontramos con normas de conducta pero que no llevan aparejadas sanciones $^{29}$. Obsérvese que son normas sobre cómo se crean normas y tienen como objeto otras normas y, por tanto, son metarreglas según nuestra definición.

Las normas de competencia hacen referencia a la finalidad que debe perseguirse. El derecho no acostumbra a ofrecer una autorización general ilimitada. La idea de competencia supone la limitación de la misma. Las constituciones y las leyes determinan el contenido material y la finalidad básica de la competencia que otorga. La finalidad puede ser establecida de forma muy genérica -como, por ejemplo, en el derecho privado la capacidad general de contratación- o de una forma más estricta la que se da normalmente en el derecho público. Por ejemplo, un gobernador civil o un alcalde tienen limitadas estrictamente sus competencias. No tienen una competencia general sobre cualquier cosa. La idea de la competencia está siempre relacionada con unos límites. Si se traspasan estos límites nos encontramos con la desviación de poder y con el no seguimiento de la regla de competencia.

También las normas de competencia de las constituciones modernas

\footnotetext{
${ }^{28}$ La teoría de la autolimitación de Jellinek trató de resolver este problema sugiriendo que el poder jurídico debería autolimitarse, pero no hay ninguna garantía jurídica que permita afirmar que todo poder estatal es poder jurídico y que no se puede dar ningún abuso de poder.

${ }^{29}$ Véase sobre las normas sin sanción el trabajo de N. Bobbio, Contribución a la Teoría del Derecho, Valencia, Fernando Torres, 1980.
} 
regulan el contenido de la legislación futura. Conviene resaltar la diferencia entre este tipo de norma y la anterior. La anterior hace referencia a cuál ha de ser el contenido y la finalidad de la norma. En el caso de la norma de competencia que ahora nos ocupa el elemento fundamental es el mandato para la creación de nueva legislación para el futuro. Es distinta la competencia que tiene un gobernador civil para garantizar el orden público que la norma constitucional o legislativa que establece un nuevo programa social contra el paro. Estas normas no autorizan sino que ordenan al legislativo a la administración una conducta determinada.

El análisis anterior muestra que en los ordenamientos positivos existen metarreglas. Estas metarreglas no tienen una estructura unitaria. En algunos casos son normas que autorizan la creación de normas, pero en otros son normas que imponen la obligación. Obligan a determinado órgano del estado a seguir una conducta determinada. También cabe destacar que su régimen jurídico no es unitario porque, en ciertos casos, su no seguimiento puede provocar la anulación, pero, ni la anulación es automática ni tampoco todas las normas de competencia que no se siguen provocan la inexistencia de la norma producida, puesto que pueden existir normas que pertenezcan a un ordenamiento y que, sin embargo, no se hayan dictado respetando las normas de producción de normas. Probablemente, estos ejemplos muestran que la doctrina ha sido excesivamente reduccionista y, por tanto, ha sido incapaz de apreciar la gran variedad de normas de competencia. También quisiera argumentar que las analogías entre el derecho y los juegos pueden conducir a confusiones. Si se juega con cinco alfiles se deja de jugar al ajedrez, pero si no se sigue una regla constitutiva, es posible que se continúe jugando al derecho -aunque sea ilegal-. A nadie puede sorprender hoy el abuso de derecho como ejemplo de juego no equitativo del derecho que produce resultados y consecuencias jurídicas. En el juego jurídico las trampas, muchas veces, no anulan el juego, sino que se continúa jugando al mismo juego.

\section{Normas de competencia de aplicación de normas}

Pero las normas de competencia son metarreglas que no sólo se ocupan de la producción de las normas nuevas, sino que también podemos descubrir -en el material preanalítico $^{30}$ - metarreglas que

\footnotetext{
${ }^{30}$ Una opinión en contra puede verse en MacCormick en su ponencia de Siena según la cual la teoría crea las normas de competencia con independencia del material preanalítico
} 
tienen como objeto la aplicación de las normas ${ }^{31}$. Así como en el parágrafo anterior nuestra preocupación era analizar las normas que tienen como objetivo la innovación del ordenamiento jurídico, ahora nos interesa ver quién, cuándo y cómo debe aplicar las normas jurídicas. Los grandes clásicos se preocuparon de este tema mostrando quiénes son los destinatarios de las normas jurídicas, es decir, a quién se dirigen, si a todos los ciudadanos, a algunos o bien a los jueces. También existen ciertas reglas que determinan los límites espaciales y temporales de la aplicación de las normas. Una de las características de los sistemas normativos jurídicos es que existen una gran cantidad de normas que determinan las instituciones aplicadoras del derecho y esas metanormas son muy variadas. Solamente quisiera recordar la importancia y la variedad de normas sobre la aplicación. Normalmente la doctrina ha tenido como modelo de metarregla este tipo de normas ${ }^{32}$.

\section{Normas sobre resolución de conflictos}

Por último, existen otras metanormas que tienen como objetivo resolver los conflictos entre normas. Los criterios tradicionales de jerarquía, especialidad y cronológico no son nada más que reglas que se incorporan a los ordenamientos jurídicos para resolver los conflictos entre normas. No interesa señalar aquí si esos metacriterios son completos o incompletos. Interesa destacar que en los ordenamientos jurídicos existen procedimientos para resolver los conflictos normativos y que los más canonizados en la actualidad son los citados aunque podrían darse otros procedimientos para resolver un

\footnotetext{
${ }^{31}$ La importancia de las normas sobre aplicación de normas no puede ser infravalorada. Véase, por ejemplo, el papel que confiere a este tipo de normas J. Raz en La Institucionalización del Derecho, en La autoridad del Derecho, pág. 143, en la que sostiene que los sistemas jurídicos no son identificados sólo por el hecho de que contienen normas que confieren poderes o facultades para procurar determinaciones aplicativas de carácter obligatorio. Los sistemas jurídicos tienen que contener normas que confieren tales poderes o facultades a instituciones (órganos centralizados que concentran en sus manos la autoridad de pronunciar determinaciones aplicativas de carácter obligatorio). Raz considera que estas instituciones aplicadoras son las necesarias para la existencia de un sistema normativo jurídico. Los sistemas jurídicos según Raz, deben tener normas que establezcan instituciones primarias, estas instituciones primarias deben tener el deber de aplicar las disposiciones y la institución primaria debe ser limitada. Además, Raz exige que el sistema sea comprehensivo, supremo y abierto para que pueda ser considerado un sistema normativo. Razreconoce la existencia de otras normas de competencia que deja fuera del análisis.

${ }^{32}$ Véase sobre este punto C. Alchourrón y E. Bulygin, Introducción a la Metodología de las Ciencias Sociales, Buenos Aires, Astrea, 1974.
} 
conflicto de normas ${ }^{33}$. Cabría incluir aquí también algunas reglas sobre la derogación en tanto puede ser pensada como una metanorma que tiene como objeto la validez de la norma objeto, aunque no existe acuerdo sobre este punto y me desviaría de mi principal ocupación tratarlo aquí. En todo caso, es posible que una contradicción entre normas de diversas jerarquía conlleve -o pueda conllevar- la derogación de una norma. La importancia de estas metarreglas para el uso del derecho ha sido reconocida en muchas ocasiones. La jerarquía del ordenamiento jurídico descansa en el sistema de garantía de recursos y las posibilidades de anulación de las decisiones desviantes de la estructura jerárquica. Algunas metanormas son necesarias para el cumplimiento de esta función. La norma que habilita a la discreción judicial también es una metarregla.

\section{La posición de las metarreglas}

Las metarreglas ocupan un lugar privilegiado en la estructura jerárquica del ordenamiento jurídico. No se trata sólo de analizar la importante función que ejercen en los sistemas normativos creando la posibilidad de la adaptación del sistema a las nuevas necesidades y, además, garantizando la estabilidad del sistema. Las normas de competencia son muy importantes por la posición jerárquica que ocupan en los ordenamientos jurídicos. Las metarreglas son lógicamente superiores en jerarquía en relación a las reglas objeto. Guastini sostiene que entre unas y otras existe la misma relación que entre el metalenguaje y el lenguaje objeto. La posición depende, por tanto, de la estructura lógica del lenguaje legal $^{34}$. Pero la cuestión que debe resolverse es la jerarquía entre las metarreglas.

$\mathrm{Y}$ eso tiene que ver con los valores que defienden los abogados. Y éstos acostumbran a distinguir una buena reconstrucción de una mala siempre y cuando exista coherencia entre la norma y el principio o conjunto de principios institucionales vigentes en una sociedad.

\footnotetext{
${ }^{33}$ Por ejemplo, se podría mantener que una norma que tiene mucha antigüedad debería prevalecer sobre una nueva norma porque la norma antigua puede ser una seña de identidad importante de la sociedad mientras que la nueva puede destruir aspectos fundamentales que siempre esta sociedad ha mantenido. El argumento de la tradición es, en muchas ocasiones, una razón excluyente o una razón que invierte la carga de la prueba. Si quieres separarte de la tradición debes mostrar por qué tu nueva propuesta es mejor. Si no lo consigues entonces debes seguir la tradición.

${ }^{34}$ Véase R. Guastini, op. cit. Véase N. Bobbio, Norma primaria y norma secundaria en su Contribución a la Teoría del Derecho, op. cit. En este trabajo insiste sobre la posición de las normas secundarias en la jerarquía del ordenamiento jurídico.
} 
Eso quiere decir que el criterio de juicio sobre una regla depende de su capacidad de adaptación al principio, o bien, en la manera que puede evitar la contradicción o inconsistencia con el mismo.

\section{Consecuencias del no seguimiento de las normas de competencia}

Guastini sugiere que se puede distinguir entre inexistencia, invalidez y sanción. El no seguimiento de una norma de competencia puede originar una de estas tres consecuencias.

Empecemos por el primer caso. ¿Qué ocurre cuando falta poder? Me parece que una respuesta inmediata es que una norma dictada por alguien que carece de autoridad o de competencia para dictarla debería ser considerada como no existente. Y ésa parece ser la tendencia general en la doctrina ${ }^{35}$. Sin embargo, eso no se adecua a los hechos porque es muy frecuente que existan normas dictadas por autoridades incompetentes y que, sin embargo, pertenezcan al ordenamiento jurídico ${ }^{36}$. Si aceptamos este criterio, una sentencia ilegal no es una sentencia y una ley inconstitucional no es una ley. Toda la discusión entre autorización formal y material puede traerse a colación para mostrar que ya, desde Kelsen, se juzga al derecho irregular como posible y que una irregularidad de este tipo no da origen inmediato a la no existencia. También vimos cómo Ross exigía una primera condición que imposibilitaba la existencia del derecho irregular ${ }^{37}$. Raz también exige que las instituciones aplicadoras del derecho deben tener la obligación de aplicar las disposiciones jurídicas. Una autoridad es incompetente si no respeta la disposición jurídica que le prohíbe ejercer competencia fuera de los límites de la suya. Sin embargo, pueden producirse consecuencias jurídicas mediante la actividad de autoridades incompetentes. Eso invalida la tesis

${ }^{35}$ La exigencia de la obligatoriedad del derecho por los autorizados por el mismo es una doctrina aceptada por muchos autores prima facie. Después cuando se analiza más de cerca existen muchas vacilaciones.

${ }^{36}$ Sobre el problema del derecho irregular véase la posición de J. Ruiz Manero en su trabajo Jurisdicción y Normas, Madrid, Centro de Estudios Constitucionales, 1991.

${ }^{37}$ Sobre este punto es iluminador el excelente trabajo de Stanley Paulson, Material and Formal Authoritation in Kelsen's Pure Theory,Cambridge Law Journal 1980 (reprint in M. Jory; Legal Positivism), en donde demuestra con argumentos poderosos cómo la cláusula alternativa y la autorización formal son fórmulas que permiten la existencia de normas que se han dictado ilegalmente. Paulson sostiene que la autorización formal juega un papel fundamental en la racionalización de los defectos en las normas jurídicas o «errores en el derecho» y sostiene que la doctrina de la alternativa no conduce al realismo como ha sostenido Juan Ruiz Manero. Véase sobre la doctrina de la alternativa mi trabajo Kelsen y la Crisis de la Ciencia Jurídica, Barcelona, Ariel, 1977, y la discusión Manero-Bulygin. 
básica de que si no se respeta la norma de competencia de atribución de poder entonces la norma no existe. Se debe analizar caso por caso y mostrar cuáles son los criterios que se utilizan para diferenciar la consecuencia «inexistencia» de los diversos grados de nulidad.

En el caso de que se viole el procedimiento parece que la respuesta debería ser que la norma producida no existe porque su existencia está en función de que haya sido creada por la autoridad competente y conforme al procedimiento preestablecido. Sin embargo, la consecuencia de la inexistencia no se produce siempre porque muchas veces se tiene en cuenta y se prioriza la finalidad sobre el seguimiento de las reglas de competencia. Parece que en ciertos casos -como, por ejemplo, en el derecho privado- si no se siguen los procedimientos preestablecidos para que un documento sea considerado un testamento entonces no existe como tal. Sin embargo, eso no es tan automático en el derecho público en el cual las autoridades pueden no respetar los procedimientos y esperar que los costes del litigio sean tan fuertes que nadie esté dispuesto a batallar contra la administración que actúa violando procedimientos. El régimen jurídico es muy distinto $\mathrm{y}$, por tanto, las consecuencias jurídicas son suficientemente importantes como para que se establezca una distinción relevante. En algunos países -como España- además la administración es inembargable y eso hace posible que a pesar de que la administración tenga una sentencia en contra no se pueda ejecutar y se esté a merced de la buena voluntad de la administración. Pero la buena voluntad no es una garantía jurídica.

El tercer caso de no seguimiento de una norma de competencia es la falta de competencia material. Ello ocurre cuando la autoridad se extralimita y va más allá del contenido concreto para lo cual ha sido habilitada. Por ejemplo, cuando la autoridad tiene competencia para la regulación del tráfico y realiza funciones de policía judicial que no le corresponden.

El cuarto caso de no seguimiento de una norma de competencia se da cuando se infringe un mandato establecido por una norma de superior jerarquía. Por ejemplo, si se prohíbe tratar cierta materia reservada y lo hace. Sin embargo, es preciso realizar una distinción porque las normas superiores muchas veces establecen obligaciones positivas a los gobiernos y estas obligaciones positivas no son exigibles jurídicamente. Los legisladores no tienen obligaciones fuertes de legislar.

Por último, cabe hablar de vicio de la regla de competencia cuando ésta no respeta los valores superiores establecidos como principios jurídicos básicos institucionales. 


\section{Conclusiones}

La tipología de normas de competencia y las consecuencias jurídicas que se pueden desprender de los casos en los cuales se presentan vicios en las normas de competencia nos pueden llevar a las siguientes conclusiones.

Primero: Las normas de competencia constituyen un conjunto de metarreglas. Tienen como objeto otras normas y no tienen un estatuto jurídico unitario. Con estatuto jurídico unitario quiero decir que no todas las normas de competencia son definiciones, o autorizaciones, o normas de conducta. Lo único que tienen en común todas las normas de competencia es su objeto: otras normas.

Segundo: En el seno de lo que hemos denominado normas de competencia existen algunas que son autorizaciones, pero no toda norma de competencia puede ser reducida a una autorización. Otras normas de competencia establecen procedimientos y en este sentido son normas de conducta. Al juez x no se le permite seguir el procedimiento de mayor cuantía en ciertos casos, sino que se le exige, y en caso contrario puede incurrir en responsabilidad. Existen también normas de competencia que hacen referencia al significado de los términos jurídicos y que no pueden ser tratadas como si fueran normas de conducta ${ }^{38}$. Por último, las normas de competencia pueden ser vistas como reglas de hacer técnico ${ }^{39}$.

Tercero: Las consecuencias jurídicas que se siguen por el no seguimiento de una norma de competencia pueden ser muy variadas. En algunos casos se produce la inexistencia. Por ejemplo, si un particular dicta una constitución o si un conjunto de personas dicta una constitución sin que exista la mínima posibilidad de que sea considerada como tal, entonces no existe la norma. Pero la distinción entre anulabilidad e inexistencia no se puede dibujar de una forma estricta. En realidad existen muchas normas que han sido creadas por autoridades incompetentes o sin seguir los procedimientos o los contenidos adecuados y forman parte del ordenamiento jurídico. El estado de derecho carece de un procedimiento jurídico que garantice la legalidad de la actuación de las autoridades que estatuye. Una posibilidad de resolver este problema es suponer que la autoridad actúa siempre legalmente, pero si estamos interesados en describir el derecho positivo entonces este supuesto exige no considerar como jurídico algo -las decisiones irregulares- que forma parte del derecho.

${ }^{38}$ Tratar a las normas de competencia como definiciones tiene sus problemas porque la función de una definición es el significado mientras que las normas tienen otras pretensiones.

${ }^{39}$ Así lo han sostenido Atienza y Ruiz Manero en su trabajo Sulle regola que conferiscono poteri, Analisi e Diritto, 1994. 
Quizá la única acotación que me parece razonable en este punto es señalar el carácter excepcional de la decisión irregular ${ }^{40}$ y que, en ningún caso, eso puede suponer una habilitación positiva por parte de la Constitución para que el juez haga lo que quiera, es decir, seguir el derecho o no seguirlo y decidir por sí mismo. Creo que un límite importante está constituido por la crítica pública. Es cierto que no existe ninguna fórmula que permita protegemos contra decisiones equivocadas del poder, pero una sociedad que posee una comunidad crítica permite disciplinar la labor de las máximas autoridades. Este límite tiene su fundamento en la bondad del argumento y todo buen constitucionalista conoce algunos argumentos desgraciados de su tribunal constitucional ${ }^{41}$. Me parece que una cosa es describir cómo es el derecho y otra muy distinta defender cómo debe actuar el juez.

El carácter privilegiado de la autoridad se manifiesta por la tendencia a considerar que su actividad siempre es legal mientras que los ciudadanos acostumbran a estar bajo sospecha. Las diferencias entre los regímenes de derecho público y derecho privado son una buena muestra de esta tesis.

Cuarto: No es cierto que la nulidad es la consecuencia de no seguir las normas de competencia como sugiere Hart, porque hay normas de competencia que son normas de conducta. Una visión que identifique normas de competencia con nulidad es excesivamente estrecha. Tampoco me parece adecuada la tesis de Guastini según la cual las normas constitutivas que no se siguen producen la inexistencia, mientras que las normas regulativas producen nulidad o sanción. Y para poder mantener esta tesis debería aclararse la distinción entre normas regulativas y constitutivas. Creo que muchas normas constitutivas son también regulativas $\mathrm{y}$, por tanto, la distinción es ambigua ${ }^{42}$.

Quinto: La distinción entre inexistencia, anulabilidad y sanción tiene un carácter gradual. Es muy posible que si en un juicio no se sigue ningún procedimiento se considere inexistente. Pero si sólo

\footnotetext{
${ }^{40}$ Véase sobre este punto S. Paulson, Material and Formal, op. cit., concluding remark, págs. 192 ys.

${ }^{41}$ Dworkin ha sido el aran defensor -en los últimos tiempos- de los buenos argumentos como sistema de control último del poder judicial o de la autoridad de última instancia frente al escepticismo o al realismo extremo. Véase su Law's Empire y su reciente Life's Dominion, págs. 145 y s., London, Harper \& Collins, 1993, en la que afirma que «We seek genuine constraints in the only place where can be found: in good argument», y poco más adelante afirma «the main engines for disciplining judges are intellectual rather than political or legal».

${ }^{42}$ Véase para una crítica de la distinción de Searle, Sauer, Playing by Rules, op. cit., pág. 7, en la que se argumenta la distinción entre reglas constitutivas y regulativas es iluminadora en cierto sentido, pero en otro es confusa porque muchas reglas constitutivas tienen su aspecto regulativo, y Raz, Razón Práctica y Normas, op. cit.
} 
existe un defecto de forma entonces ya pasamos a la categoría de la anulabilidad con efectos ex nunc o ex tunc. En cuanto al incumplimiento de una metarregla que es una norma de conducta tampoco es muy claro que la sanción se produzca, puesto que es difícil castigar al poder y exigirle responsabilidades. Normalmente se presupone que no se puede cometer ilegalidad desde el poder y se responsabiliza al individuo, pero el propio poder puede ser responsable de su actividad.

Sexto: La tesis de que las normas de competencia que confieren poderes o las definiciones son inviolables y que, por tanto, si no se siguen producen necesariamente inexistencia es falsa, porque pueden pertenecer al ordenamiento jurídico normas que se han dictado fuera del cauce de las normas de competencia. 
DOXA 15-16 (1994) 